Oncology

\title{
Analysis of Germline Gene Copy Number Variants of Patients with Sporadic Pancreatic Adenocarcinoma Reveals Specific Variations
}

\author{
Daniele Fanale $^{\mathrm{a}}$ Juan Lucio lovannac Ezequiel Luis Calvo ${ }^{c, d}$ \\ Patrice Berthezene ${ }^{c}$ Pascal Belleau ${ }^{d}$ Jean Charles Dagorn ${ }^{c}$ Chiara Ancona $^{a}$ \\ Giovanna Catania ${ }^{a}$ Paolo D'Alia ${ }^{a}$ Antonio Galvano ${ }^{a}$ Eliana Gulotta ${ }^{a}$ \\ Silvia Lo Dico ${ }^{a}$ Francesco Passiglia ${ }^{a}$ Giuseppe Bronte ${ }^{a}$ Massimo Midirib \\ Giuseppe Lo Re ${ }^{b}$ Giuseppe Cicero ${ }^{a}$ Viviana Bazan $^{a} \quad$ Antonio Russo $^{a}$ \\ a Section of Medical Oncology, Department of Surgical, Oncological and Stomatological Sciences, and ${ }^{\text {b Department }}$ \\ of Radiology, Department of Biopathology and Medical and Forensic Biotechnologies, University of Palermo, \\ Palermo, Italy; ' INSERM U624, Stress Cellulaire, Parc Scientifique et Technologique de Luminy, Marseille, France; \\ ${ }^{\mathrm{d}}$ Molecular Endocrinology and Oncology Research Center, Centre Hospitalier Université Laval Research Center, \\ Quebec, Que., Canada
}

\section{Key Words}

Copy number variations - Cancer-associated genes .

Germline alterations · Sporadic pancreatic cancer

\begin{abstract}
Objectives: The rapid fatality of pancreatic cancer is, in large part, the result of diagnosis at an advanced stage in the majority of patients. Identification of individuals at risk of developing pancreatic adenocarcinoma would be useful to improve the prognosis of this disease. There is presently no biological or genetic indicator allowing the detection of patients at risk. Our main goal was to identify copy number variants (CNVs) common to all patients with sporadic pancreatic cancer. Methods: We analyzed gene CNVs in leukocyte DNA from 31 patients with sporadic pancreatic adenocarcinoma and from 93 matched controls. Genotyping was performed with the use of the GeneChip Human Mapping 500K Array Set (Affymetrix). Results: We identified 431 single nucleotide polymorphism (SNP) probes with abnormal hy-
\end{abstract}

bridization signal present in the DNA of all 31 patients. Of these SNP probes, 284 corresponded to 3 or more copies and 147 corresponded to 1 or 0 copies. Several cancer-associated genes were amplified in all patients. Conversely, several genes supposed to oppose cancer development were present as single copy. Conclusions: These data suggest that a set of 431 CNVs could be associated with the disease. This set could be useful for early diagnosis.

(c) 2013 S. Karger AG, Basel

\section{Introduction}

Pancreatic cancer represents 3\% of all new cases of cancer but leads to $5 \%$ of all cancer deaths [1]. In the general population, it carries a lifetime risk of approximately $1 \%$ [2]. Environmental factors such as cigarette smoking

D.F. and J.L.I. contributed equally to this work.

\section{KARGER}

() 2013 S. Karger AG, Basel

$0030-2414 / 13 / 0855-0306 \$ 38.00 / 0$

E-Mail karger@karger.com

www.karger.com/ocl
Antonio Russo, $\mathrm{MD}, \mathrm{PhD}$

Section of Medical Oncology

Department of Surgical, Oncological and Stomatological Sciences

University of Palermo, Via del Vespro 129, IT-90127 Palermo (Italy)

E-Mail antonio.russo@usa.net 
[3] or diseases such as diabetes [4], obesity [5] or chronic pancreatitis [6] predispose pancreatic cancer. Familial factors are also involved in the susceptibility to pancreatic cancer [7]. The lifetime risk of pancreatic cancer is $4.7 \%$ for first-degree relatives of pancreatic cancer cases and increases with each family member who is affected. Pancreatic cancer can also be inherited as part of a multicancer syndrome such as that associated with BRCA2 mutations [8], Peutz-Jeghers syndrome [9], and familial atypical mole and melanome syndrome [10]. In these cases, the family pedigree shows evidence of other cancers such as breast or intestinal tumors, or melanomas, in addition to pancreatic tumors. However, the vast majority of pancreatic cancers are sporadic. The molecular mechanisms by which they occur involve alterations in somatic gene expression, which include KRAS2, BRCA2 and TP53 mutations, telomere shortening, p21 and cyclin D1 upregulations, inactivation of $\mathrm{p} 16^{\mathrm{INK} 4} / \mathrm{CDKN} 2 \mathrm{~A}$ and DPC4/ SMAD4, and expression of proliferation antigens [11]. The discovery of a gene (or genes), which causes sporadic pancreatic adenocarcinoma when altered in the germline, would provide important insight into the biology of the disease. In addition, the altered gene would be a useful marker allowing early detection of the disease. Therefore, the identification of such gene(s) is a priority for scientists and physicians who hope to change the dismal prognosis of this cancer.

Recently, several studies have discovered an abundance of submicroscopic copy number variations (CNVs) of DNA segments ranging from kilobases to megabases in size [12]. Deletions, insertions, duplications and complex multisite variants, collectively termed 'copy number variations', were found in all humans [13]. New arraybased technologies can detect differences in DNA copy number at much higher resolution than cytogenetic methods [14], and hence, might reveal previously unidentified spontaneous mutations. In the last years, genome analysis provided a powerful approach to test for evidence of genetic variations within and between geographical regions and local populations [15]. In a recent work, Chen et al. [16] reported that whereas the overall $\mathrm{CNV}$ frequencies are similar between populations, their distribution is highly specific to the population of origin. Recently, Huang et al. [17] reported that pancreatic cancer risk is significantly associated with a $\mathrm{CNV}$ at $6 \mathrm{q} 13$ (CNVR2966.1) through a long-range transcriptional regulation of $C D K N 2 B$ that shows lower transcriptional levels in pancreatic tissues of individuals with low copy number ( 1 or 0 ). Furthermore, in 2009, Amundadottir et al. [18] identified a single nucleotide polymorphism
(SNP) that maps the first intron of the $\mathrm{ABO}$ blood group gene which is significantly associated with pancreatic cancer, suggesting that people with blood group $\mathrm{O}$ may have a lower risk than those with groups A or B. However, the involvement of this SNP in the susceptibility to pancreatic cancer remains to be established [18].

In this work, we used the Affymetrix platform (Affymetrix Inc., Santa Clara, Calif., USA) to genotype 500,000 unique SNPs. The median physical distance between SNPs is $2.5 \mathrm{~kb}$ and the average distance between SNPs is $5.8 \mathrm{~kb}$. These techniques have shown an abundance of CNVs in humans [19], and the same methods have been used to find de novo chromosome aberrations below the resolution of microscopy in children with mental retardation and dysmorphic features $[20,21]$, including patients with syndromic forms of autism [22]. We have performed high-resolution genomic microarray analysis on 31 patients with sporadic pancreatic adenocarcinoma to determine the rate of de novo $\mathrm{CNV}$ and found that patients affected with this disease show several common CNVs that are absent in individuals without apparent disease.

\section{Materials and Methods}

\section{Acquisition of Samples}

The study was approved by the appropriate institutional review board at each participating site. Written informed consent was obtained from all participants. Between March 13 and June 26, 2012, we prospectively collected 31 DNA samples from peripheral leukocytes from patients with a diagnosis of sporadic pancreatic adenocarcinoma. Patients with a familial pancreatic cancer history were excluded. Diagnosis of adenocarcinoma was confirmed by histologic analysis. All clinical information for every enrolled patient was entered in an anonymous and coded format. All DNA samples were of sufficient quality to be genotyped. Twenty-four patients were European (20 from Palermo and 4 from Barcelona) and 7 were Japanese (as self-reported in the presence of the physician). Of these patients, 18 were men and 13 were women, with a mean age of 62 years. Control DNAs from individuals without cancer, matched by sex and ethnic origin, were used. For each patient with pancreatic adenocarcinoma, we randomly selected 3 individuals with no history of cancer as controls. As a reference set, we used the HapMap database [23].

\section{CNV Analysis}

DNA was extracted from whole blood of patients with pancreatic adenocarconoma using the QIAamp mini kit (Qiagen, Chatsworth, Calif., USA), according to the manufacturer's instructions. The DNA yields and purity were determined spectrophotometrically by measuring the absorbance of aliquots at 260 and 280 $\mathrm{nm}$. DNA was prepared for microarray hybridization using the Affymetrix GeneChips Human Mapping 500K Set (Affymetrix) as previously described by Pugh et al. [24]. The raw images were an- 
Fig. 1. Common CNVs in 31 patients with pancreatic adenocarcinoma. The number of SNP probes with abnormal signal hybridization (copy number difference of 2) that were common between patients is presented.

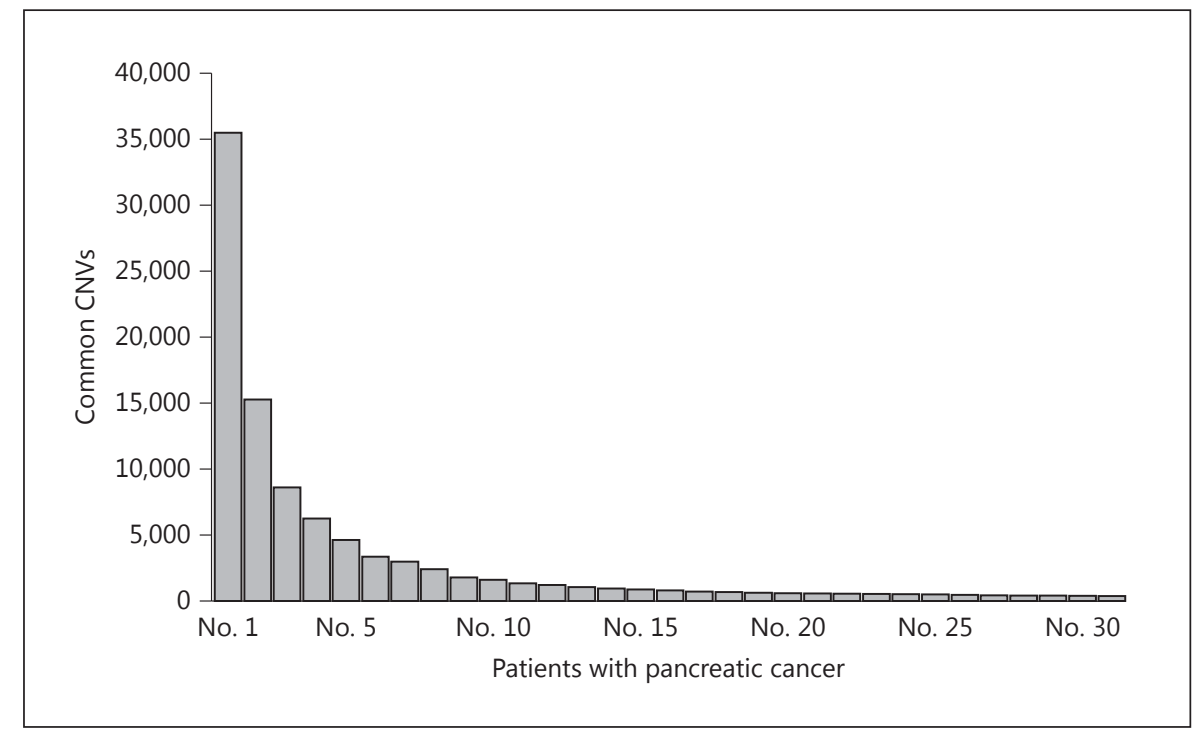

alyzed using the GeneChip operating software (GCOS version 1.4.1) and GTYPE (version 4.1) software (Affymetrix). We excluded those samples with a genotype call rate $<93 \%$. To assess copy number alterations, we used the CNAT (version 4.0.1) software. We set the genomic smoothing at $0.01 \mathrm{Mb}$ and kept the default parameters for the other variables. Copy number estimates were done using data from 172 HapMap samples as a reference. Chromosome $\mathrm{X}$ was not analyzed to avoid gender-related complications. The reproducibility of the method was assessed by analyzing 6 DNAs from patients with pancreatic adenocarcinoma in duplicate and we found that $>96 \%$ of CNVs were confirmed in both assays.

\section{Data Analysis}

Using the SAS software and ad hoc programs, individual tables generated by CNAT (CNAT version 4.0.1) were merged and SNPs were ranked according to their copy number value. Two lists containing the SNPs with copy number gains ( 3 or 4 copies) or losses ( 1 or 0 copies) were generated. In order to keep all CNVs, even single SNPs, and at the same time to avoid false-positive changes due to random noise in signal intensity, we only kept the SNPs with the same condition, i.e. gain or loss, in all 31 patients. Thereafter, selected SNP probes were merged with their respective gene annotations and physical positions according to the National Center for Biotechnology Information human genome sequence (Build 36.1, March 2006) using the NetAffx web server (Affymetrix).

\section{Results}

\section{CNVs in Patients with Pancreatic Adenocarcinoma}

The main goal of this work was to identify CNVs shared by patients with sporadic pancreatic adenocarcinoma to be used as markers of the disease and to identify the perturbations in intracellular pathways that could lead to the disease. The analysis revealed that the number of abnormal SNP probe hybridization signals, relative to the HapMap set, ranged from 22,284 to 56,664 (median value 33,621 ) in patients with sporadic pancreatic cancer. Several of them were common to all patients. When looking at how the number of common SNPs with an abnormal signal evolved with the number of patients included in the study, we observed a sharp decrease from 35,490 to 3,371 upon inclusion of the first 6 patients, then a much slower decrease to 431 when the number of patients was increased to 31 (fig. 1). We chose to work with the set defined by the 31 patients, although including more patients might allow us to select a smaller set of common SNP probes. Data from the 7 Japanese patients did not influence the results (data not shown) suggesting that the set of SNP probe variants common to all patients does not reflect their belonging to a particular ethnic group. To our knowledge, the only feature that the 31 patients have in common is that they present pancreatic adenocarcinoma, suggesting that the set of common CNVs reveals a predisposition to this disease. The set included 431 probes, of which 284 were found amplified (3 copies or more; online suppl. table 1; see www.karger.com/doi/10.1159/000354737 for all online suppl. material) and 147 showed 1 copy or none (online suppl. table 2). These probes corresponded to an increased number of alleles for 85 genes and to an allele loss or a deletion for 72 genes (table 1; online suppl. table 3 ). In a restricted number of cases, probes located to the same gene appeared with a different copy number for the same patient. 
Table 1. Genes that show CNV gain or loss in all 31 patients with pancreatic adenocarcinoma

\begin{tabular}{ll}
\hline CNV gain & ABCA13, ACVR1C, ADRA2C, AGMAT, ALDH1L1, ALS2CR12, ASIP, ATXN2L, C11orf39, C13orf28, C4orf23, \\
& C5orf30, C9orf139, C9orf21, CAND1, CCDC37, CDC14B, CENPE, CHD9, CSMD2, CTBP1, CXCL14, DACH1, DLC1, \\
& EIF2S2, EMB, FAM135B, FCHO1, FGF20, FLJ35424, FLJ38723, FPGT, FUT7, FZD10, GNLY, GPC5, GPC6, GPX7, \\
& GTF3C3, HABP4, HCN1, HNT, IMMP2L, IRX1, KCTD8, KLF15, KLHL1, KPNA1, LEPREL1, LOC153328, \\
& LOC154907, LOC340069, LRFN2, LRP1B, LRRN3, MAP1S, MGC21675, MSR1, N4BP3, NAT8L, NBPF11, NDST1, \\
& NLF2, NOTCH3, PAPPA2, PCDH9, PRDM16, RAB21, RPS14, SFTPB, SOX1, SYT1, TMEM19, TULP3, TYW1, UPP1, \\
& VAC14, VSNL1, WDR78, WHSC2, ZCCHC11, ZNF134, ZNF211, ZSCAN4, ZWINT \\
\hline CNV loss & ABCF1, AIG1, ALDH2, ASH1L, C10orf59, C20orf11, C6orf134, C6orf136, C9orf86, CBARA1, CD9, CENTG2, CHRNE, \\
& CYP2A13, DDR1, DHH, DHX16, DNAJB12, DNMT1, DUOX2, DUOXA1, ERAF, FAM55C, FBXO2, FBXO44, FIGN, \\
& FLJ20294, FLOT1, GBE1, GCS1, GMCL1, GNL1, GRB14, GRM3, HLA-E, HPGD, IER3, JSRP1, KIAA0922, KIAA1712, \\
& KLHL14, LMBR1L, LOC90826, LPXN, MAP3K7, MDC1, MINK1, MRPS18B, MYO9B, NR4A3, NRM, OAZ1, OR5B21, \\
& OSR2, PFKL, PLD2, PPP1R10, PRR3, RAMP1, RAP1GDS1, RHEBL1, RHOU, SGPL1, SH3BP4, SNX27, SOX6, TLR2, \\
& TUBB, VRK1, VWF, ZCCHC7, ZEB2
\end{tabular}

Genes Whose Allele Number Is Altered in Patients with Pancreatic Adenocarcinoma

Identification of genes implicated in the CNVs of patients with pancreatic adenocarcinoma could be useful for diagnostic purposes, to understand the physiopathology of this cancer and, eventually, to target these genes in therapeutic strategies. For diagnostic purposes, altered DNA dosage that affects regions containing genes or intergenic regions is indifferent. By contrast, to get insight into the pathophysiology of the disease, only CNVs that affect genes are of interest. We found that several genes encoding cancer-associated products such as $C D C 14 B$, CENPE, EIF2S2, FGF20, FZD10, GTF3C3, KLHL1, NOTCH3, RAB21, TULP3, VSNL1 and ZWINT were amplified in all 31 patients with pancreatic cancer included in this study. In addition, 15 genes encoding putative proteins with unknown function were also found amplified in all 31 patients. The products of other known genes found amplified are involved in intracellular signaling, cell-to-cell or cell-to-extracellular matrix interactions. They also included structural proteins, secretory proteins, receptors, metabolic enzymes, enzymes involved in posttranslational modifications, transcriptional factors or nuclear proteins, but their direct relationship with carcinogenesis is not formally established. On the other hand, 10 genes supposed to act against cancer development (ASH1L, CD9, GRB14, IER3, LPXN, MAP3K7, $M D C 1, M I N K 1, S G P L 1$ and VRK1) were present as single copy in the genome of all 31 patients with pancreatic adenocarcinoma. Several genes encoding intracellular signaling factors, structural proteins, secretory proteins, receptors, metabolic enzymes, or transcriptional factors also showed allele loss. Finally, 10 genes with unknown

CNVs in Sporadic Pancreatic Cancer function showed allele loss in all patients. The role of these proteins in cancer remains to be established.

It is also important to note that several important genes involved in cancer were amplified in 30 of 31 patients, such as BMP1, EGFL11, FLT4, FOSB, KIT, MAP4K4, MYB, PDGFRA and TGFA, and 30 of 31 patients had lost one allele of the Myc inhibitor PAK2. Finally, ARRB2 was deleted in 29 of 31 patients and AKT3 and KRAS were amplified in 28 of 31 patients. The list of genes with an abnormal copy number is presented in online supplementary table 4 .

\section{Specificity of the Repertoire of CNVs in Patients with} Sporadic Pancreatic Cancer

Ninety-three individuals apparently free of any disease, matched with pancreatic cancer patients, were used as controls. They were randomly divided into 3 groups of 31 individuals and their DNAs were investigated for the presence of common SNP probes with abnormal hybridization signal. To our surprise, finding common CNVs among these individuals was exceptional, in strong contrast with data obtained in patients developing pancreatic adenocarcinoma. The highest score observed was 21 SNP probes common to 31 controls. When two thirds of DNA samples were randomly replaced in each group by samples from the other 2 groups, results were very similar (data not shown). The next step was to look whether the set of CNVs common to all patients with sporadic pancreatic cancer could be observed in the DNA of the 93 individuals used as controls. To this end, the SNPs from the selected set of 431 probes were analyzed in each control patient. None of them showed a similar profile. In fact, the highest number of abnormal signals in common 
with the 431 SNPs typical of patients found in a control was only 24 (approximately 5\%) as shown in online supplementary table 5 . These data suggest that the set of CNVs detected in patients with sporadic pancreatic adenocarcinoma is powerfully associated with the disease.

\section{Discussion}

Pancreatic adenocarcinoma may be sporadic or of familial origin, including patients with a multi-cancer syndrome. To our present knowledge, sporadic cases represent $90 \%$ of all pancreatic cancers. Sporadic pancreatic adenocarcinoma development may be associated with environmental factors or with some pancreatic diseases [25] but, in this context, predisposition due to a peculiar genetic background is also suspected. In this work, we report that patients developing sporadic pancreatic adenocarcinoma have in common a series of DNA structural variations that are not observed in control patients. Identification of this CNV set may be used for the diagnosis of an individual with a genetic predisposition to develop sporadic pancreatic cancer, for understanding the physiopathology of this disease and also to target these genes in a preventive strategy.

Pancreatic cancer has one of the most terrible prognoses. One of the reasons is that diagnosis occurs when almost all therapeutic strategies are ineffective. In this context, the possibility to identify patients with a predisposition to the disease would certainly be helpful. In a previous study, Lucito et al. [26] reported that patients with a familial history of pancreatic cancer showed a total of 56 unique germline genomic regions with $\mathrm{CNV}$ s that were not present in controls, including 31 amplifications and 25 deletions. Interestingly, when we compared the common genes presumably involved in the development of familial [26] or sporadic pancreatic cancer (this work), we found no common genes suggesting that the development of these cancers occurs through different pathways. This observation is in agreement with the fact that environmental factors are associated with sporadic cancer but have little impact, if any, on the occurrence of the familial disease [11]. An attractive hypothesis is that genomic alterations associated with inherited pancreatic cancer have sufficient penetrance to trigger the disease, whereas alterations associated with sporadic pancreatic cancer require the additional influence of environmental factors to allow cancer development.

It is known that cancer occurs in about $20 \%$ of individuals. If predisposition to cancer is the consequence of a series of inherited genetic abnormalities, in a group of individuals chosen at random, the corresponding set of genetic abnormalities should be shared by an equivalent percentage of individuals. This was not the case in the set of the 93 control DNAs that we analyzed. We did not find any subset of CNVs in such proportion, suggesting that there is no genetic predisposition to cancer but that more specific sets of genetic abnormalities will predispose to cancers of specific organs; the set of 431 SNP probes associated with pancreatic cancer identified in this study is an example of such specificity.

Mechanistically, how might CNVs be involved in complex disease? When deletions or duplications are present within a gene or its regulatory regions, they will probably generate an imbalance in the corresponding RNA level and consequently in the level of the encoded product. For genes and pathways in which the amount of a functional product is critical, it seems likely that CNVs could account for individual variations in the susceptibility to the disease [27]. In this paper, we report that several genes involved in cancer development show specific structural variations. We also identified several candidate genes not yet associated with pancreatic cancer development. These genes will be further studied as candidates that could favor cancer development.

In summary, we report that a restricted set of SNP probes with abnormal hybridization signals is found in germline DNA of all patients with sporadic pancreatic adenocarcinoma included in our study, but not in unaffected patients. This set might be used as a diagnostic tool.

\section{Disclosure Statement}

The authors declare no conflict of interest.

References

1 Siegel R, Naishadham D, Jemal A: Cancer statistics, 2012. CA Cancer J Clin 2012;62:10-29.

$\checkmark 2$ Chappuis PO, Ghadirian P, Foulkes WD: The role of genetic factors in the etiology of pancreatic adenocarcinoma: an update. Cancer Invest 2001;191:65-75.

- 3 Momi N, Kaur S, Ponnusamy MP, Kumar S, Wittel UA, Batra SK: Interplay between smoking-induced genotoxicity and altered signaling in pancreatic carcinogenesis. Carcinogenesis 2012;33:1617-1628.

4 Chari ST, Leibson CL, Rabe KG, Timmons LJ, Ransom J, de Andrade M, Petersen GM: Pancreatic cancer-associated diabetes mellitus: prevalence and temporal association with diagnosis of cancer. Gastroenterology 2008; 134 : 95-101. 
5 Larsson SC, Orsini N, Wolk A: Body mass index and pancreatic cancer risk: a meta-analysis of prospective studies. Int J Cancer 2007; 120:1993-1998.

6 Malka D, Hammel P, Maire F, Rufat P, Madeira I, Pessione F, Levy P, Ruszniewski P: Risk of pancreatic adenocarcinoma in chronic pancreatitis. Gut 2002;51:849-852.

7 Vincent A, Herman J, Schulick R, Hruban RH, Goggins M: Pancreatic cancer. Lancet 2011;378:607-620.

-8 Lal G, Liu G, Schmocker B, Kaurah P, Ozcelik H, Narod SA, Redston M, Gallinger S: Inherited predisposition to pancreatic adenocarcinoma: role of family history and germ-line p16, BRCA1, and BRCA2 mutations. Cancer Res 2000;60:409-416.

$>9$ Giardiello FM, Brensinger JD, Tersmette AC, Goodman SN, Petersen GM, Booker SV, Cruz-Correa M, Offerhaus JA: Very high risk of cancer in familial Peutz-Jeghers syndrome. Gastroenterology 2000;119:1447-1453.

10 Goldstein AM, Fraser MC, Struewing JP, Hussussian CJ, Ranade K, Zametkin DP, Fontaine LS, Organic SM, Dracopoli NC, Clark $\mathrm{WH}$ Jr, et al: Increased risk of pancreatic cancer in melanoma-prone kindreds with p16INK4 mutations. N Engl J Med 1995;333: 970-974.

-11 Hezel AF, Kimmelman AC, Stanger BZ, Bardeesy N, Depinho RA: Genetics and biology of pancreatic ductal adenocarcinoma. Genes Dev 2006;20:1218-1249.

-12 Conrad DF, Pinto D, Redon R, Feuk L, Gokcumen O, Zhang Y, Aerts J, Andrews TD, Barnes C, Campbell P, Fitzgerald T, Hu M, Ihm CH, Kristiansson K, Macarthur DG, Macdonald JR, Onyiah I, Pang AW, Robson S, Stirrups K, Valsesia A, Walter K, Wei J, Tyler-Smith C, Carter NP, Lee C, Scherer SW, Hurles ME: Origins and functional impact of copy number variation in the human genome. Nature 2010;464:704-712.
13 Bruder CE, Piotrowski A, Gijsbers AA, Andersson R, Erickson S, Diaz de Stahl T, Menzel U, Sandgren J, von Tell D, Poplawski A, Crowley M, Crasto C, Partridge EC, Tiwari H, Allison DB, Komorowski J, van Ommen GJ, Boomsma DI, Pedersen NL, den Dunnen JT, Wirdefeldt K, Dumanski JP: Phenotypically concordant and discordant monozygotic twins display different DNA copy-number-variation profiles. Am J Hum Genet 2008;82:763-771.

14 Feuk L, Carson AR, Scherer SW: Structural variation in the human genome. Nat Rev Genet 2006; 7:85-97.

15 Huang RS, Chen P, Wisel S, Duan S, Zhang W, Cook EH, Das S, Cox NJ, Dolan ME: Population-specific GSTM1 copy number variation. Hum Mol Genet 2009; 18:366-372.

6 Chen W, Hayward C, Wright AF, Hicks AA, Vitart V, Knott S, Wild SH, Pramstaller PP, Wilson JF, Rudan I, Porteous DJ: Copy number variation across European populations. PLoS One 2011;6:e23087.

17 Huang L, Yu D, Wu C, Zhai K, Jiang G, Cao G, Wang C, Liu Y, Sun M, Li Z, Tan W, Lin D: Copy number variation at $6 \mathrm{q} 13$ functions as a long-range regulator and is associated with pancreatic cancer risk. Carcinogenesis 2012; 33:94-100.

-18 Amundadottir L, Kraft P, Stolzenberg-Solomon RZ, Fuchs CS, Petersen GM, Arslan AA, Bueno-de-Mesquita $\mathrm{HB}$, et al: Genome-wide association study identifies variants in the $\mathrm{ABO}$ locus associated with susceptibility to pancreatic cancer. Nat Genet 2009;41:986-990.

19 Iafrate AJ, Feuk L, Rivera MN, Listewnik ML, Donahoe PK, Qi Y, Scherer SW, Lee C: Detection of large-scale variation in the human genome. Nat Genet 2004;36:949-951.

20 Koolen DA, Vissers LE, Pfundt R, de Leeuw N, Knight SJ, Regan R, Kooy RF, Reyniers E, Romano C, Fichera M, Schinzel A, Baumer A, Anderlid BM, Schoumans J, Knoers NV, van Kessel AG, Sistermans EA, Veltman JA, Brunner HG, de Vries BB: A new chromosome $17 q 21.31$ microdeletion syndrome associated with a common inversion polymorphism. Nat Genet 2006;38:999-1001.

-21 Shaw-Smith C, Pittman AM, Willatt L, Martin H, Rickman L, Gribble S, Curley R, Cumming S, Dunn C, Kalaitzopoulos D, Porter K, Prigmore E, Krepischi-Santos AC, Varela MC, Koiffmann CP, Lees AJ, Rosenberg C, Firth HV, de Silva R, Carter NP: Microdeletion encompassing MAPT at chromosome $17 q 21.3$ is associated with developmental delay and learning disability. Nat Genet 2006;38: 1032-1037.
22 Jacquemont ML, Sanlaville D, Redon R, Raoul O, Cormier-Daire V, Lyonnet S, Amiel J, Le Merrer M, Heron D, de Blois MC, Prieur M, Vekemans M, Carter NP, Munnich A, Colleaux L, Philippe A: Array-based comparative genomic hybridisation identifies high frequency of cryptic chromosomal rearrangements in patients with syndromic autism spectrum disorders. J Med Genet 2006;43:843-849.

23 Redon R, Ishikawa S, Fitch KR, Feuk L, Perry $\mathrm{GH}$, Andrews TD, Fiegler H, Shapero MH, Carson AR, Chen W, Cho EK, Dallaire S, Freeman JL, Gonzalez JR, Gratacos M, Huang J, Kalaitzopoulos D, Komura D, MacDonald JR, Marshall CR, Mei R, Montgomery L, Nishimura K, Okamura K, Shen F, Somerville MJ, Tchinda J, Valsesia A, Woodwark C, Yang F, Zhang J, Zerjal T, Armengol L, Conrad DF, Estivill X, Tyler-Smith C, Carter NP, Aburatani H, Lee C, Jones KW, Scherer SW, Hurles ME: Global variation in copy number in the human genome. Nature 2006;444:444-454.

24 Pugh TJ, Delaney AD, Farnoud N, Flibotte S, Griffith M, Li HI, Qian H, Farinha P, Gascoyne RD, Marra MA: Impact of whole genome amplification on analysis of copy number variants. Nucleic Acids Res 2008;36:e80.

-25 Wang DS, Wang ZQ, Zhang L, Qiu MZ, Luo HY, Ren C, Zhang DS, Wang FH, Li YH, Xu $\mathrm{RH}$ : Are risk factors associated with outcomes in pancreatic cancer? PLoS One 2012;7: e41984.

26 Lucito R, Suresh S, Walter K, Pandey A, Lakshmi B, Krasnitz A, Sebat J, Wigler M, Klein AP, Brune K, Palmisano E, Maitra A, Goggins M, Hruban RH: Copy-number variants in patients with a strong family history of pancreatic cancer. Cancer Biol Ther 2007;6:15921599.

27 Freeman JL, Perry GH, Feuk L, Redon R, McCarroll SA, Altshuler DM, Aburatani H, Jones KW, Tyler-Smith C, Hurles ME, Carter NP, Scherer SW, Lee C: Copy number variation: new insights in genome diversity. Genome Res 2006;16:949-961. 